\title{
A divided working class? planning and career perception in the service and working classes
}

\section{- Yaojun Li}

University of Manchester, UK

I Frank Bechhofer

University of Edinburgh, UK

- Robert Stewart

MVA Scotland, UK

I David McCrone

University of Edinburgh, UK

I Michael Anderson

University of Edinburgh, UK

I Lynn Jamieson

University of Edinburgh, UK

\begin{abstract}
The contrast between the service class and the working class is central to much class analysis. This structural distinction, based on differences in the employment relationship, is analytically powerful, has validity, and is not in question here. The working class, however, is not homogeneous in all respects. This paper focuses on a sizeable group within the working class who perceive themselves as having (or having had) a career. As well as having this perception, they exhibit a forward-looking perspective, both in the world of employment and with regard to more general planning. They demonstrate degrees of planning, in work and non-work areas, strikingly comparable to service class respondents, and significantly greater than working class respondents without career perceptions. They believe that they can achieve their plans and indeed some have done so successfully. This exercise of forethought is materially aided by this group's possession of rather greater resources of various kinds than the rest of the working class. But this is by no means the whole story. The findings suggest strongly that a willingness to exercise or not to exercise forethought sharply distinguishes two groups within the working class, and may indicate a significant and hitherto unreported cleavage worthy of further investigation.
\end{abstract}

\section{KEY WORDS}

career perceptions / class cleavages / forethought / planning / service class / working class 


\section{Introduction}

$\mathrm{n}$ the last 15 years much work in the field of class analysis has centred on the contrast between the service class, comprising professional, administrative and managerial employees, and the working class, composed of skilled, semi-skilled and unskilled workers. This emphasis owes much to the employment relationship theory developed by Goldthorpe and his colleagues (see, for instance, Goldthorpe, 1982, 1987, 1995). Central to the argument is the distinction between the employment relationship of the service class as typified by current rewards, future compensations and embedded career structures, and the labour contract relationship of the working class which offers poorer rewards and hardly ever involves the specification of future compensations or career structures. Erikson and Goldthorpe lay particular emphasis on what they characterize as 'important prospective elements - for example, salary increments on an established scale, assurances of security both in employment and, through pension rights, after retirement, and, above all, well-defined career opportunities' (1992: 42, emphasis in the original). As one would expect, survey evidence has shown that those in the service class are more likely than those in the working class to perceive themselves as having a career (see for instance, Anderson et al., 1994: 32; Marshall et al., 1988: 74-8).

The extent to which the classification of occupations by Goldthorpe and his colleagues ${ }^{1}$ has criterion and construct validity has been explored by Evans (1992), and Evans and Mills (1998) who have carried out careful and detailed secondary analysis of the 1984 Social Class in Modern Britain survey (Marshall et al., 1988). In the conclusions to their methodologically sophisticated 1998 paper they state that:

...occupational classes defined in terms of clusters of job characteristics can be observed, and these classes correspond, to a reasonable degree, to those identified by the less formal procedures adopted by Goldthorpe and his colleagues when constructing the schema.

They go on to say that 'on the whole, therefore, in terms of both criterionrelated and construct validity the schema seems adequate' (1998: 101). In particular, although Evans and Mills identify some problems and ambiguities with the full schema, the validity of the distinction between service and working classes is upheld. At a detailed level, they note that 'with the working class we also found no clear way of distinguishing skilled from semi- and unskilled manual workers' (1998:102). Using a somewhat different methodological approach, Evans reached a similar conclusion in an earlier paper commenting that his work 'supports the strategy of aggregating those pairs of classes to form the "salariat" and the "working class"' (Evans, 1992: 227).

The structural distinction between the service and working classes is analytically powerful, and is not in question here. Nevertheless, a too ready acceptance of broad structural patterns can lead researchers to overlook interesting 
divergences from the expected pattern, and we shall focus in the body of the paper on one such anomaly: a sizeable group within the working class shares with the service class a tendency to exercise forethought in significant ways over the medium or longer term.

We are drawing here on a rather less well-developed stream of research which has focused on individual and household plans and strategies, and the ways in which these are employed to help people organize their way through everyday life in the short term, usually in the medium term and, for some groups, even through the entire life course (see for instance Anderson et al., 1994, 2002; McCrone, 1994; Morris, 1989; Pahl, 1984).

We have, however, moved away from too sharp a distinction between plans and other forward looking aspects of people's thinking and behaviour, such as ambitions, general long term goals, aspirations and so on. These conceptual distinctions in the way that people view the future are not necessarily distinct in the minds of respondents, nor is it always possible or useful to slice the complexities of everyday forward thinking in these ways. Our emphasis is on the general concept of forethought and the ways in which people in different structural situations attempt to and are able to exercise forethought in order to control their progress through life as best they can.

In this paper we bring data to bear on differences between the working and the service class, but more especially on the question of a division within the working class. Our earlier work (Anderson et al., 1994) suggested that people in the service class were more likely to plan their work and family lives in a more active way, and our recent work supports that finding. However, in these areas of life as elsewhere, class by no means explains everything.

In particular, there is, as we shall see, a significant sub-section of the working class in our study who perceive themselves as having (or having had) a career. This perception is associated with a range of other plans, ambitions, general long term goals, aspirations and so on - in brief, with a forward looking perspective. This sub-section of the working class, on a range of measures related to forethought, resembles more closely members of the service class than the remainder of the working class.

This paper is in no way intended as a contribution to the literature about career such as is contained for instance in Arthur et al. (1989). That literature, while generally concerned with middle class occupations, shows that there is by no means just one unified conception of a 'career' (see, for instance, Halford and Savage, 1995; Mills, 1995). Our focus is on the extent to which perceiving oneself as having or having had a career involves, now or in the past, a forward looking and fairly long term time perspective of a kind usually associated with those in service class positions. ${ }^{2}$ Although we are starting from a survey question about perceiving oneself as having a career, it is the association, in our data, of this perception with a range of other measures of forethought which is of importance, rather than the single issue of perceiving oneself as having a career. 


\section{Data and methods}

The data come from two surveys: 'Individual and Household Strategies: A Decade of Change?' (1997), and 'Telling the Future: Individual and Household Plans among Younger Adults' (1999). We shall refer to them as 'DCS' and 'TTF' respectively. ${ }^{3}$ DCS is a follow-up study of Kirkcaldy respondents to the Social Change and Economic Life Initiative (SCELI, 1986, 1987), ${ }^{4}$ re-interviewed in the summer of 1997, and has an age range of 30-70 for the original respondents and 28-81 for their partners. TTF is a new study in the same area but on a younger cohort interviewed in the summer of 1999, with an age range of 20-30 for the respondents and 18-48 for the partners. ${ }^{5}$

The focus of both surveys is on how and in what ways people plan in all major aspects of their work and family lives. The surveys also contain data on employment status and occupational characteristics (from which social classes are derived $)^{6}$ and on the social, cultural and demographic characteristics of our respondents. Data for the two surveys are always presented separately and here we do not focus at all upon or seek to explain differences between the two data sets. ${ }^{7}$ Instead the arguments in the article depend on relationships shown within each of the two samples. We thus generally seek to show relationships within DCS, which covers a much greater age range, in the first instance; the TTF data enable the reader to check whether the general conclusions also hold, as they generally do, for a 20-29 age group.

Both studies were based on the Kirkcaldy Travel to Work Area, which, typical of many areas in Scotland and the UK as a whole, has witnessed a shift over the past 30 years from a declining 'older' economy, based largely on heavy industry and manufacturing, towards an expanding mixed economy based largely on electronics and the service sector. In 1997, based on official employment rates, Kirkcaldy TTWA had slightly higher than average levels of unemployment $(8.6 \%)$ compared with county (Fife) $(7.9 \%)$, Scottish $(6.8 \%)$ and UK $(5.9 \%)$ rates at the time, and had been consistently above the Scottish and UK rates since 1985 .

The question of representativeness is frequently raised in a study of this kind. The Social Change and Economic Life Initiative was carried out in six areas of Britain, and the work histories and attitudes data did not differ sharply between them. Because the data on plans and forethought on which we report here were collected in a follow-up study in the one area only, we cannot test the findings across the SCELI areas. However, in the original SCELI study, some of the detailed material on individual and household plans was collected in all six areas, and in our earlier analysis we did not find it necessary to differentiate between the areas; others drew similar conclusions (see, for instance, the tables in Gallie and Vogler (1994: 141-4), and the brief discussion and tables in Gallie (1996: 164-6). Further, our argument rests on relationships between variables, often after controlling for structural variables of a kind that tend to vary between areas. We thus feel reasonably confident that a similar study carried out in other parts of Britain would show broadly similar patterns. 


\section{Analysis}

We shall briefly set the scene by showing the strong and expected association between class position and career perception. ${ }^{8}$ The paper then focuses on three major groups - those working class respondents who form a 'deviant group' in that they perceive themselves as having or having had a career, hereafter called the $\mathrm{WC}(\mathrm{Y})$ group; working class respondents with no such career perceptions, the $\mathrm{WC}(\mathrm{N})$ group; and service class respondents with career perceptions, the $\mathrm{SV}(\mathrm{Y})$ group.

\section{Class and career perception}

There is a very strong, and statistically significant association between objective social position and whether respondents believe themselves to have or to have had a career. ${ }^{9}$ In DCS, four out of five service class respondents report that they have or have had a career $(83 \%)$ but only a quarter of those in working class positions hold such perceptions (25\%). In TTF, the figures are 96 and 56 percent respectively. ${ }^{10}$

Table 1 shows how service and working class respondents who do, or do not, perceive themselves as having or having had a career are distributed in the sample. Whenever a powerful association exists, such as that between class and perceiving oneself as having a career, it is often of sociological interest to analyse the 'deviant case', and this is the prime purpose of this paper. We focus on that 'deviant' group within the working class who perceive themselves as having a career. Logically, of course, we would wish also to examine those within the service class who do not perceive themselves as having a career, but numbers in our samples are too small to allow this. Our principal attention therefore will be on differences within the working class. We explore the extent to which the working class group who perceive themselves as having or having had a career, resemble the equivalent service class group more closely than they do their working class counterparts. The areas we shall examine in order to do this include attitudes to work, past and prospective employment plans, and forethought more generally.

Table I Class and career perception (percentage by column)

\begin{tabular}{|c|c|c|c|}
\hline & & $\begin{array}{l}\text { DCS } \\
\%\end{array}$ & $\begin{array}{l}\text { TTF } \\
\%\end{array}$ \\
\hline Service class with perceived career & SV(Y) & 24 & 18 \\
\hline Service class with no perceived career & $\mathrm{SV}(\mathrm{N})$ & 5 & 1 \\
\hline Intermediate class & INT & 16 & 24 \\
\hline Working class with perceived career & $W C(Y)$ & 14 & 32 \\
\hline Working class with no perceived career & $\mathrm{WC}(\mathrm{N})$ & 42 & 26 \\
\hline$(\mathrm{N})$ & & $(30 I)$ & $(252)$ \\
\hline
\end{tabular}

Note: In this and some of the tables within this article, percentages may not add up to 100 because of rounding. 


\section{Structural differences in the three main groups}

It is important in what follows to bear in mind that certain structural factors differentiate between the three main groups, and some key aspects of this are shown in Table 2.

Table 2 Social, cultural and demographic features of respondents in different class and career perception combinations (percentage by column except for mean age, SD and $\mathrm{N}$ )

\begin{tabular}{|c|c|c|c|c|c|c|}
\hline & \multicolumn{3}{|c|}{$D C S$} & \multicolumn{3}{|c|}{ TTF } \\
\hline & $S V(Y)$ & $W C(Y)$ & $W C(N)$ & $S V(Y)$ & $W C(Y)$ & $W C(N)$ \\
\hline Mean age & 51 & 48 & 52 & 25 & 25 & 26 \\
\hline (SD) & $(I 1.6)$ & $(12.1)$ & $(11.6)$ & (3.4) & $(3.1)$ & $(4.4)$ \\
\hline$(N)$ & (7I) & $(42)$ & (125) & (44) & $(80)$ & $(65)$ \\
\hline \multicolumn{7}{|l|}{ Education $^{\mathrm{a}}$} \\
\hline Degree/Prof & 58 & 7 & 2 & 55 & 3 & 2 \\
\hline $\mathrm{A} / \mathrm{H}+\mathrm{O}$ levels & 25 & 29 & 25 & 41 & 52 & 34 \\
\hline Voc + None & 17 & 64 & 73 & 5 & 46 & 65 \\
\hline$(N)$ & (7I) & $(43)$ & (125) & $(44)$ & $(8 I)$ & $(65)$ \\
\hline \multicolumn{7}{|l|}{ Class of origin } \\
\hline Service & 30 & 6 & 5 & 47 & 28 & 13 \\
\hline Intermediate & 36 & 31 & 18 & 26 & 31 & 18 \\
\hline Working & 34 & 63 & 77 & 28 & 42 & 70 \\
\hline$(N)$ & $(67)$ & $(35)$ & (II5) & $(43)$ & (72) & $(56)$ \\
\hline \multicolumn{7}{|l|}{ Class in $1987^{b}$} \\
\hline Service & 64 & 5 & 1 & & & \\
\hline Intermediate & 14 & 21 & 9 & & & \\
\hline Working & 23 & 74 & 90 & & & \\
\hline$(N)$ & $(66)$ & $(38)$ & (122) & & & \\
\hline \multicolumn{7}{|l|}{ Employment $^{c}$} \\
\hline In work & 96 & 86 & 66 & 93 & 70 & 46 \\
\hline Unemployed & 2 & 7 & 7 & 5 & 6 & 20 \\
\hline Non-employed & 2 & 7 & 27 & 2 & 25 & 34 \\
\hline$(N)$ & (55) & (29) & (73) & (44) & (8I) & $(65)$ \\
\hline
\end{tabular}

Notes: In this and other tables, the Ns vary somewhat owing to missing data, inevitable in surveys of this complexity. In the analysis we have deleted cases 'pairwise' in order to minimize loss of data in what is a relatively small survey. It has been argued (Little and Rubin, 1987: 40-42) that listwise deletion may also be more likely to induce bias.

In this table, in order to bring out the crucial differences more clearly, we present the data only for the three groups on which we focus primarily in this paper - SV(Y),WC(Y) and WC(N).

a Education refers to the highest educational qualifications obtained: university degree or professional qualifications in law, medicine, teaching or nursing; A-Level, Higher Grade or O-Level; vocational training or no qualifications.

b Some of the original respondents in DCS changed partners or partnership status between 1987 and 1997; the class positions in 1987 of these partners are not available.

c The self-employed and employed are combined; retired respondents are omitted from the analysis. 
Age is clearly not an important factor differentiating the three groups. Within each data set, the mean ages are fairly similar and any differences nonsignificant. ${ }^{11}$ In both data sets, the $\mathrm{SV}(\mathrm{Y})$ group are far more likely than the working class respondents as a whole to possess advanced educational qualifications, to have come from advantaged family backgrounds and, in DCS where we have the relevant data, to have occupied service class positions a decade earlier. ${ }^{12}$ They are much less likely to hold only vocational or no educational qualifications, and to come from working class backgrounds. ${ }^{13}$ That much is to be expected; the important question for our argument here is whether the $\mathrm{WC}(\mathrm{Y})$ group shows similar structural differences when compared to the $\mathrm{WC}(\mathrm{N})$ group. Across all the comparisons of structural advantage and disadvantage for the above three variables, the $\mathrm{WC}(\mathrm{Y})$ group indeed fares consistently somewhat better across many of them and worse on none of them, although the differences are generally much less dramatic than those between the $\mathrm{SV}(\mathrm{Y})$ group and the working class ones. ${ }^{14}$

The data relating to the labour market in Table 2 are especially important for our argument in this paper. In both surveys the $\mathrm{WC}(\mathrm{Y})$ group is considerably more likely than the $\mathrm{WC}(\mathrm{N})$ group to be in employment. These differences are statistically significant, while, interestingly, that between the $\mathrm{SV}(\mathrm{Y})$ and $\mathrm{WC}(\mathrm{Y})$ groups in DCS is not. ${ }^{15}$

More generally, Anderson et al. (1994) showed how the possession of resources of all kinds, and thus class, was linked to planning in general. Our present research, with its specific focus on planning, has confirmed that resources of all kinds are indeed necessary for long term planning. The $\mathrm{WC}(\mathrm{Y})$ group are better resourced than the $\mathrm{WC}(\mathrm{N})$ group. In particular their income is higher, especially in DCS, where 60 percent of the $\mathrm{WC}(\mathrm{Y})$ group, compared with only 29 percent of the WC(N) group have a standardized mean income above the median for the sample. ${ }^{16}$ The corresponding figures for TTF $(46 \%$ and $33 \%$ ) show a similar but smaller difference. The $\mathrm{SV}(\mathrm{Y})$ group, as one would expect, fare much better with 83 percent in DCS and 94 percent in TTF above the median. ${ }^{17}$ The two working class groups also differ in one other interesting and related aspect to which we shall return later. The $\mathrm{WC}(\mathrm{Y})$ group are much less likely to have semi-skilled or unskilled jobs. In DCS, semi- and unskilled workers form 51 percent of the $\mathrm{WC}(\mathrm{Y})$ and 85 percent of the $\mathrm{WC}(\mathrm{N})$ group; in TTF, the figures are 63 and 86 percent. Both represent significant differences.

Believing oneself to have a career involves some sense of a perspective over time. The greater labour market and financial power of the $\mathrm{WC}(\mathrm{Y})$ group compared to the $\mathrm{WC}(\mathrm{N})$ group potentially gives them more of the necessary resources required to plan ahead. Is it then the case that for the former group, perception of career is part of a wider set of orientations and perspectives on life? Are they differentiated in this way from the WC(N) group, demonstrating comparable degrees of active planning to the $\mathrm{SV}(\mathrm{Y})$ group despite being less advantaged? 


\section{Class position, career perception and the realm of work}

Table 3 presents data on attitudes to work, work plans and expectations of achieving them, and past work plans and achievements. In terms of attitudes to work, we differentiate between those who would and those who would not continue to work (not necessarily in the same job) even if they were to get enough money to live as comfortably as they would like for the rest of their lives. ${ }^{18}$ The former group thus place great weight on the 'intrinsic' aspects of work. The balance between 'intrinsic' and 'extrinsic' is clearly weighted towards the 'extrinsic' in the latter group. Data on 'future plans and confidence' are derived from a series of questions about respondents' work life plans for the next five years and the likelihood of their fulfilment; data on 'past plans and achievements' (for DCS only) are derived from a series of questions concerning their work-life plans at their entry to the labour market, and the degree of success they have had in achieving these plans over their working lives thus far. ${ }^{19}$

In both samples, the WC(Y) group were far more likely to say they would continue to work than the $\mathrm{WC}(\mathrm{N})$ group, and differ very little from the $\mathrm{SV}(\mathrm{Y})$ group.

The data on work plans also present a striking picture. Looking first at whether respondents have work plans and are confident of achieving them over the next five years, in DCS there is a 26 percentage point difference between the two working class groups, but a negligible two percentage point difference between the $\mathrm{WC}(\mathrm{Y})$ and $\mathrm{SV}(\mathrm{Y})$ groups. ${ }^{20}$ In TTF the gap between the SV(Y) and $\mathrm{WC}(\mathrm{Y})$ groups is much larger $(21 \%)$, but crucially the 28 percentage point gap between the latter group and their working class counterparts with no career perceptions is as large as in DCS.

The retrospective data in DCS show a dramatic contrast in the 'Nplans Njobs' category, referring to the statements that the respondents 'had no idea about what they wanted to do with their life at the start of work', and 'have had to take whatever jobs have turned up'. One third of the $\mathrm{WC}(\mathrm{N})$ group respond in this way, compared with a minimal 7 and 3 percent of the $\mathrm{WC}(\mathrm{Y})$ and $\mathrm{SV}(\mathrm{Y})$ groups. Indeed the working class and service groups with career perceptions look very similar at all levels of the variable and are differentiated throughout from the WC(N) group. While it is likely that the ambitions of the working class will have been more modest than those of the service class, the relative success of the $\mathrm{WC}(\mathrm{Y})$ group in formulating and achieving them contrasts sharply with the failure of the $\mathrm{WC}(\mathrm{N})$ group to do so. One can also sense that the WC(N) group had been frustrated and disappointed in the course of their working lives, often having to take whatever jobs turned up, to face unemployment, or leave the labour market for non-employment.

\section{Time span of planning}

As we noted earlier, in one of the first studies on individual and household plans and strategies using survey data, Anderson et al. (1994: 20) point out that indi- 
Table 3 Class, career perception and work (percentage by column)

\begin{tabular}{|c|c|c|c|c|c|c|}
\hline & \multicolumn{3}{|c|}{ DCS } & \multicolumn{3}{|c|}{ TTF } \\
\hline & $S V(Y)$ & $W C(Y)$ & $W C(N)$ & $S V(Y)$ & $W C(Y)$ & $W C(N)$ \\
\hline \multicolumn{7}{|l|}{ Attitudes to work ${ }^{\mathrm{a}}$} \\
\hline Would continue & 53 & 48 & 25 & 75 & 65 & 48 \\
\hline Would not continue & 47 & 52 & 75 & 25 & 35 & 52 \\
\hline$(N)$ & (55) & $(29)$ & (73) & $(44)$ & $(8 I)$ & $(65)$ \\
\hline \multicolumn{7}{|c|}{ Future plans and confidence ${ }^{b}$} \\
\hline Confident & 73 & 71 & 45 & 84 & 63 & 35 \\
\hline Doubtful & 16 & 18 & 20 & 14 & 25 & 26 \\
\hline Take whatever & 2 & II & 20 & 2 & 12 & 29 \\
\hline Don't intend & 9 & 0 & 16 & 0 & 0 & 9 \\
\hline$(N)$ & (55) & $(28)$ & (7I) & $(44)$ & $(8 I)$ & $(65)$ \\
\hline \multicolumn{7}{|c|}{ Past plans and achievements ${ }^{c}$} \\
\hline Yplans Yjobs & 38 & 29 & 16 & & & \\
\hline Nplans Yjobs & 31 & 31 & 27 & & & \\
\hline Yplans Njobs & 28 & 33 & 23 & & & \\
\hline Nplans Njobs & 3 & 7 & 34 & & & \\
\hline$(N)$ & (7I) & $(42)$ & $(125)$ & & & \\
\hline
\end{tabular}

Notes: In this table, in order to bring out the crucial differences more clearly, we present the data only for the three groups on which we focus primarily in this paper, namely $S V(Y), W C(Y)$ and $W C(N)$.

a The questions were asked of the non-retired respondents only in DCS.

b The questions ask the respondents whether they have plans for their working lives over the next five years and whether they think they will be able to carry out such plans:

'Confident': respondents both have such plans and are confident of realising them;

'Doubtful': respondents have plans but are seriously doubtful whether they will be able to implement them;

'Take whatever': respondents either have no clear plans or have serious doubts, and expect that they will just have to take whatever comes up;

'Don't intend': respondents do not intend to work within next five years.

(The questions were asked of the non-retired only in DCS.)

c The questions in DCS from which the variable is derived explore the employment experiences of the respondents throughout their working lives. Respondents are asked whether they had work-related plans when they first started work and how such plans have turned out:

'Yplans Yjobs': respondents had such plans at the start of work and have been able to get the jobs they have wanted;

'Nplans Yjobs': respondents had no such plans at the start of work but have generally been able to get the jobs they have wanted;

'Yplans Njobs': respondents had such plans at the start of work but have not been able to get the jobs they have wanted;

'Nplans Njobs': respondents had no such plans at the start of work and have not been able to get the jobs they have wanted.

viduals and social collectivities may formulate conscious and rational plans in order 'to structure, in a coherent way, actions within a relatively long-term perspective' (emphasis added). We have already noted that believing one has or had a career is linked to relatively long-term thinking and planning in the occupational sphere at least. Does this pattern extend to more general long term planning, and how do the $\mathrm{WC}(\mathrm{Y})$ group measure up against their service class counterparts? 
Table 4 Class, career perceptions and time span of planning (percentage by row)

\begin{tabular}{lcccccccr}
\hline & \multicolumn{4}{c}{ DCS } & \multicolumn{5}{c}{ TTF } \\
& Years & Months & Weeks & $N$ & Years & Months & Weeks & \multicolumn{1}{c}{$N$} \\
\hline SV(Y) & 38 & 48 & 14 & $(7 I)$ & 43 & 25 & 32 & $(44)$ \\
SV(N) & 33 & 33 & 33 & $(15)$ & 0 & 50 & 50 & $(2)$ \\
INT & 21 & 31 & 48 & $(48)$ & 23 & 35 & 42 & $(60)$ \\
WC(Y) & 33 & 26 & $4 I$ & $(42)$ & 33 & 24 & 43 & $(81)$ \\
WC(N) & 11 & 30 & 58 & $(125)$ & 8 & 31 & 61 & $(64)$ \\
$(N)$ & $(70)$ & $(103)$ & $(128)$ & $(301)$ & $(65)$ & $(72)$ & $(114)$ & $(25 I)$ \\
$(\%)$ & $(23)$ & $(34)$ & $(43)$ & $(100)$ & $(26)$ & $(29)$ & $(45)$ & $(100)$ \\
\hline
\end{tabular}

Table 4 shows the time span of planning ${ }^{21}$ associated with each of the class and career perception groups. The variable is divided into planning ahead at least one year or more for some things (years), planning only a few months ahead (months), and planning only a few weeks ahead or less (weeks). The questions from which this variable is derived do not focus on specific areas or activities and were intended to tap a general propensity for long-term planning.

Once again the working class is highly differentiated with regard to long term planning. Working class respondents with career perceptions showed themselves to be three to four times more likely to engage in long-term planning than their counterparts without career perceptions, differences which are highly significant (at the $1 \%$ level in DCS and $0.1 \%$ level in TTF). Further, in both data sets, the $\mathrm{WC}(\mathrm{Y})$ group were fairly close to the $\mathrm{SV}(\mathrm{Y})$ group in their general propensities for long-term planning. While there are differences, they are not statistically significant.

It might be objected that merely looking at the groups formed by the intersection of class and career perception is to neglect other, on the face of it more likely, factors affecting long-term planning. For instance, previous studies, such as that by Anderson et al. (1994) noted earlier, have shown rather marked differences by partnership, age and, to some extent, gender in planning behaviours. Does the diversity of the working class persist after controlling for such factors by using a logistic regression analysis?

Table 5 shows the striking results obtained using the time span of planning variable as described above, with planning in 'years' as the response variable, and class and career perception groups, educational qualifications, gender, employment and partnership status as explanatory variables. It is remarkable that not one of the control variables turns out to be significant; and that the impact of perceiving oneself to have a career is made even stronger after the controls.22 Thus, in DCS, working class respondents with career perceptions were about four times more likely to plan long term than their counterparts with no career perceptions, and the $\mathrm{SV}(\mathrm{Y})$ group were only slightly more so (about 5.5 times); in TTF, the figures are five and seven times respectively. 
Table 5 Parameter estimates of the effects of social, cultural and demographic factors $\mathrm{s}^{\mathrm{a}}$ on longterm planning

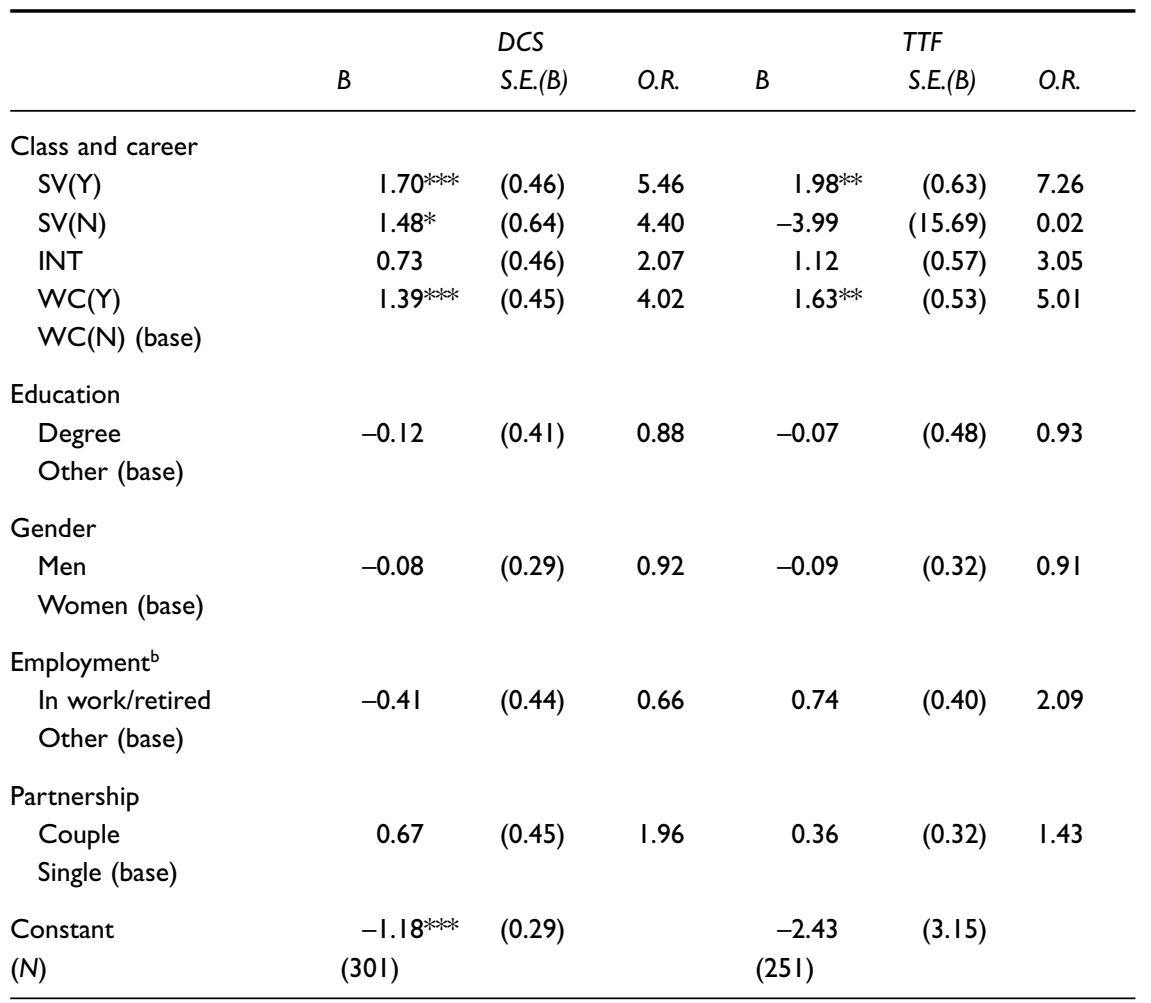

Notes: B - coefficient or log odds

S.E.(B) - standard error of B

O.R. - odds ratio or exponentiated $B$

$*_{p}<0.05 * * p<0.01 * * * p<0.001$

${ }^{a}$ Age is not included in the model. However, controlling for 4 age groups $(30-39 ; 40-49 ; 50-59 ; 60+)$ in DCS, or

2 age groups $(19-24 ; 25+)$ in TTF, makes no difference to the patterns.

${ }^{b}$ In DCS, the self-employed, employees and retired (SERs) are contrasted with the unemployed and non-

employed (UNs). In TTF, the contrast is between SEs and UNs. Contrasting the SEs with the UNRs in DCS yields basically the same results.

\section{Discussion}

We do not seek to question the general importance of the structural distinction between the service and working classes. This should not, however, be taken to imply that the working class is homogeneous in all respects. ${ }^{23}$ Our analysis suggests that a significant division within the working class exists between those who do and those who do not believe themselves to have (or have had) a career. This is especially interesting because career structures are an intrinsic part of the Goldthorpe schema itself. Nor is this group with career perceptions an insignificant proportion of the working class in these two samples, comprising as it 
does a quarter in the group aged 30-70, and over half in the younger cohort aged $20-30 .{ }^{24}$ This is in the context of the overall proportion for the two samples being 47 percent and 67 percent.

We cannot interpret the higher figures in the younger cohort with any certainty, especially as age is not a differentiating factor in the older group (see Appendix). That the difference is in part at least a period effect is suggested by the comment in Rose (2000: 5) that 'thanks simply to occupational change, the proportion of the employed population now (2000) thinking they have a career is probably around 60 percent or more, not the bare 50 percent in SCELI (1985)'. It is possible that youthful optimism plays a part and also that the increased emphasis on the provision of careers advice in schools and adult education encourages forethought about employment and this way of thinking. Trefor Lloyd in a qualitative study of 63 young men aged 16-22, but mainly aged 18-20, found that without exception they made a sharp distinction between 'career jobs' and 'crap jobs', which they experienced as different labour markets. The motivations for taking the latter were always to do with money, but working in them was 'very often the strongest motivation for many of the young men to return to college or to pursue a career'. Lloyd further comments that it 'stirred them to think about the future and what they would like to do' (Lloyd, 1999: 21).

The WC(Y) group as a whole not only perceive themselves as having a career, but differ from the rest of the working class in related ways. They demonstrate degrees of planning in work and non-work areas generally comparable to service class respondents with career perceptions, and significantly greater than those working class respondents without career perceptions. Their exercise of forethought is materially aided by possession of markedly greater resources than the rest of the working class.

Structural distinctions within the working class seem to be operating here to some extent. The WC(Y) group are more likely to be skilled working class, ${ }^{25}$ and to that extent their perceptions of having a career are likely to be built on greater power in the labour market, as well as a greater likelihood of being in a secure job, of obtaining satisfaction from the job and possibly commitment to it. ${ }^{26}$ However, as we indicated earlier, Evans and Mills (1998) suggest that a sharp distinction between skilled workers and the rest of the working class cannot be sustained in terms of their employment characteristics, one of which is seeing oneself as being on a career ladder. It is thus improbable that the crucial variable distinguishing the $\mathrm{WC}(\mathrm{Y})$ group so clearly from the $\mathrm{WC}(\mathrm{N})$ group is simply skill and position in the labour market. Further, their resources, as shown earlier, remain somewhat less in terms of income and markedly worse in terms of education than those of the service class which the $\mathrm{WC}(\mathrm{Y})$ group resemble with regard to foresight and planning.

Crucially, then, associated with this perception of having (or having had) a career, there seems to be a set of aspirational factors, and a tendency for these respondents to make plans in the hope of achieving their goals. The variable stands as a proxy for a much more general disposition to plan across a wide 
range of activities, including work, to believe that one can achieve these plans and indeed for some respondents to have done so successfully.

On the basis of our data, comprehensive as it is, we can, in the last resort, only encourage further research by speculating on the factors that may underlie the tendency for this subgroup of working class respondents to plan to a greater extent than the rest of the working class. As we noted above, they are much more likely to say they would go on working even if they had no further need to earn a living, and there is some indication in the intensive interviews that they have had varied work histories, sometimes including jobs in the 'intermediate' category. We have shown that this $\mathrm{WC}(\mathrm{Y})$ group is much more likely to have plans for their working lives and to be confident of achieving them. It is then possible that this distinctive group within the working class is marked out by its members having achieved some degree of control over their working lives and success in achieving their goals. Another interesting hypothesis is that this reflects some socio-cultural aspect of their occupational, kinship or leisure social networks. Complex network processes which encourage friendship homogamy may result in some groups of working class people following each other's example and providing support to each other in the whole business of planning their individual and household lives.

What is clear, however, is that this overlooked group in the working class who perceive themselves to have or have had a career merits further enquiry. ${ }^{27}$ Our findings suggest that a willingness to exercise or not to exercise forethought sharply distinguishes two groups within the working class and may indicate a hitherto unreported division of some significance.

\section{Appendix}

As stated in the text, the logistic regression reported in Table A1 shows that after controlling for education, gender and employment status, class of origin and age, service class respondents are about nine times in DCS and eight times in TTF more likely than working class respondents to hold career perceptions.

However, despite the dominance of the class effect, the impact of other factors merits brief comment. In DCS, holders of a degree or similar professional qualification are about four times, and men about two times more likely to have career perceptions than their respective reference groups, holding constant the other factors in the model. These effects of education and gender are present, but weaker and not statistically significant in TTF. Being in employment has an effect on perceiving oneself as having a career in both DCS and TTF though it is only significant in TTF. It is striking that coming from service class origins has a much more powerful (and significant) effect in our younger sample (TTF) than the older (DCS). It seems that family resources, whether social, cultural or economic, may influence people's career perceptions or work-life trajectories when they are at a relatively young age (Bourdieu, 1984; Devine, 1998; Goldthorpe et al., 1987), whereas later in life their own achievements come to be of greater importance. 
Table Al Parameter estimates of the effects of social, cultural and demographic factors on career perception

\begin{tabular}{|c|c|c|c|c|c|c|}
\hline & & DCS & & & TTF & \\
\hline & $B$ & S.E.(B) & $O . R$ & B & S.E.(B) & $O . R$. \\
\hline Class & & & & & & \\
\hline Service & $2.20 * * * *$ & $(0.4 I)$ & 9.01 & $2.09 * *$ & $(0.80)$ & 8.05 \\
\hline Intermediate & $1.45 * * *$ & $(0.38)$ & 4.27 & $0.4 I$ & $(0.36)$ & 1.50 \\
\hline Working (base) & & & & & & \\
\hline Education & & & & & & \\
\hline Degree & $1.44 * *$ & $(0.57)$ & 4.23 & 0.89 & $(0.82)$ & 2.43 \\
\hline Other (base) & & & & & & \\
\hline Gender & & & & & & \\
\hline Men & $0.68 *$ & $(0.31)$ & 1.98 & 0.36 & $(0.33)$ & 1.44 \\
\hline Women (base) & & & & & & \\
\hline Employment & & & & & & \\
\hline In work/retired ${ }^{a}$ & 0.87 & $(0.49)$ & 2.39 & $0.76^{*}$ & $(0.33)$ & 2.14 \\
\hline Other (base) & & & & & & \\
\hline Class of origin & & & & & & \\
\hline Service & 0.35 & $(0.5 \mathrm{I})$ & 1.42 & $0.99 *$ & $(0.42)$ & 2.68 \\
\hline Intermediate & 0.02 & $(0.35)$ & 1.02 & 0.54 & $(0.37)$ & 1.72 \\
\hline Working (base) & & & & & & \\
\hline $\mathrm{Age}^{\mathrm{b}}$ & & & & & & \\
\hline $30-39$ & 0.46 & $(0.47)$ & 1.58 & & & \\
\hline $40-49$ & 0.08 & $(0.43)$ & 1.08 & & & \\
\hline $50-59$ & 0.48 & $(0.40)$ & 1.61 & & & \\
\hline $60+$ (base) & & & & & & \\
\hline Constant & 0.46 & $(0.32)$ & & $1.59 * * *$ & $(0.4 I)$ & \\
\hline$(N)$ & $(276)$ & & & $(230)$ & & \\
\hline
\end{tabular}

Notes: B - coefficient or log odds

S.E.(B) - standard error of B

O.R. - odds ratio or exponentiated $B$

$*_{p}<0.05 * * \mathrm{p}<0.01 * * * \mathrm{p}<0.001$

${ }^{a}$ In DCS, the self-employed, employees and retired (SERs) are contrasted with the unemployed and nonemployed (UNs). In TTF, the contrast is between SEs and UNs.

${ }^{b}$ With only 7 people (partners of cohabiting or married respondents) in TTF aged over 30, we have not included age as a separate category in the model. Including age, categorized as 19-24 and 25+ produces the same patterns.

\section{Acknowledgements}

This paper, like all those arising from this project, is the product of a collegiate form of working in which the fieldwork, the analysis and the drafts of the papers have been discussed by the entire research team throughout. The first two authors have been responsible for initially drafting this paper, carrying out analyses and revisions 
and seeing it into print; the names of the other authors are in random order. The data come from two studies: 'Individual and Household Strategies: A Decade of Change?' (1997) and 'Telling the Future: Individual and Household Plans among the Younger Adults' (1999), funded by the Economic and Social Research Council (ESRC) (R000236922 and R000238020). Michael Anderson, Frank Bechhofer and David McCrone are principal investigators for both studies. Lynn Jamieson joined the second project as principal investigator. Robert Stewart and Yaojun Li were research fellows on both projects. The questionnaires for both surveys were designed by the research team and the fieldwork carried out by Public Attitude Surveys (PAS). We are grateful to the Institute for Social and Economic Research at the University of Essex, and especially Dr Heather Laurie and Dr Jonathan Burton, for helping commission and pilot the surveys, data checking and cleaning, and carrying out the occupational coding. We wish to thank the journal's three referees for some helpful comments, and our colleague Professor Lindsay Paterson for expert advice and support on a number of statistical issues.

\section{Notes}

1 The classification is known under various names. As Goldthorpe himself puts it: 'The schema is known, in consequence of its rather complex genesis, by several different names. In a British context it is usually referred to as the Goldthorpe schema; in an international context, as the EGP (EriksonGoldthorpe-Portocarero) schema, the Erikson-Goldthorpe schema, or the CASMIN schema, after its use in the Comparative Analysis of Social Mobility in Industrial Societies Project' (2000: 206n). In the paper we follow the British convention.

2 Professor Michael Rose of the University of Bath, who has carried out extensive research on careers, suggests that perceiving oneself as having a career involves having more of a plan about work as a whole, taking a strategic approach, even if a rudimentary one, rather than an opportunist involvement in work, as was particularly the case for less qualified women 25 years back (personal communication).

3 In addition to the survey data, we have conducted over 70 semi-structured interviews with our respondents and their partners (if in couples) in which we explored, in great detail, various aspects of their work and non-work plans. We do not have space here to report on these interviews, but they do increase our confidence in the validity of our conclusions from the survey data.

4 DCS is an ESRC funded project (R000236922), 'Individual and Household Strategies: a decade of change?'. The study sought to re-interview a sample of households first interviewed in Kirkcaldy, Fife, as part of the Social Change and Economic Life Initiative (SCELI). The Kirkcaldy element of SCELI interviewed 1011 randomly selected respondents, aged 20-60 in 1986, with 309 of the same respondents and their partners (where present) being interviewed further in 1987. For sampling procedures in SCELI, see Gallie et al., 1994. We attempted to trace the 309 respondents, excluding 36 who said in the 1987 survey that they did not wish to be involved further. We traced 220 of the 273 , a success rate of 81 percent, but further movement and death had removed 21 
before we commenced interviewing. One hundred and eighty of this remaining 199 were successfully re-interviewed, a success rate of 90.5 percent. Interviews were also held with partners, where available, and the total number of interviewees was 301 .

5 TTF is also an ESRC funded project (R000238020), 'Telling the Future: Individual and Household Plans among the Younger Adults'. Two hundred and four randomly selected households were interviewed (110 single and 94 couple households), an effective response rate of 53 percent, but we failed to obtain full interviews with 30 partners from the couple households. We thus have data on 268 individuals.

6 We use the three-way class schema of the 'service class'; the 'intermediate class'; and the 'working class' devised by Goldthorpe and his colleagues. Females in lower-grade, routine-non-manual positions are, following Erikson and Goldthorpe (1992), grouped into the working class. Respondents who are retired, unemployed or non-employed are allocated 'class' positions on the basis of their last main jobs. Class of origin is coded in the same way and follows the 'dominance' approach (Erikson, 1984; Goldthorpe et al., 1987).

7 In particular we would be very wary of drawing any inferences about age effects from differences which exist solely between the DCS and TTF samples. There are very few age effects within DCS (respondents aged 30-70) and while it is in principle possible that differences between DCS and TTF arise because of age, this would imply some kind of caesura after age 30 which seems improbable, if only because it is very hard to see why it should exist. We are inclined to seek the explanation in the very different nature of the two samples. They were obtained in quite different ways, DCS being a follow-up of traceable SCELI respondents and TTF an entirely new sample. The response rates were considerably different, and the second survey was carried out some time after the first.

8 That class is indeed by far the most powerful of a number of objective factors which might be associated with career perception, is further confirmed by carrying out a logistic regression which shows the effects of class on career perception 'net' of education, gender and employment status, class of origin and age (see the Appendix for details and a brief discussion). After controlling for these factors, service class respondents are about nine times in DCS and eight times in TTF more likely than working class respondents to hold career perceptions.

9 The relevant questions are:

(DCS) Do you see yourself as having (or having had) a career? (Yes, No, Don't Know); and

(TTF) Do you see yourself as having a career? (Yes, No, Don't Know).

In the analysis, 'No' and 'Don't Know' are combined. Significance was tested using a difference of proportions test; $\mathrm{p}<.001$

10 The figures for the service class are somewhat higher than the 74 percent reported by Marshall et al. (1988, reworked from Tables 4.6 and 4.9) and the 78 percent by Anderson et al. (1994: 32).

11 Using a difference of means test.

12 These differences are all significant at the 0.1 percent level. 
13 Differences are significant at the 0.1 percent level in both data sets for education and in DCS for class of origin.

14 Only four are statistically significant. In terms of advantages, the WC(Y) group in TTF fares better than the $\mathrm{WC}(\mathrm{N})$ group in coming from service class families; significant at the 5 percent level. In terms of disadvantages, the $\mathrm{WC}(\mathrm{Y})$ group fares better in three of the comparisons, in being in working class positions in DCS, in coming from working class backgrounds, and in having only vocational or no qualifications in TTF; significant at the 0.1 percent, 5 percent and 5 percent levels respectively. Once again we would caution against drawing any conclusions about an age effect from the somewhat larger differences in TTF than in DCS - see endnote 7 above.

15 In DCS, the retired are omitted from this variable.

16 For the definition and coding procedures used for standardized household mean income, see Kempson et al. (1994: 268) and Anderson et al. (2000: note 9).

17 The differences between the $\mathrm{SV}(\mathrm{Y})$ and the $\mathrm{WC}(\mathrm{Y})$ groups are significant at the 0.1 percent level; those between the two working class groups are not significant in TTF, but are significant in DCS.

18 The question was originally asked in the SCELI in 1986. In both DCS and TTF, the questions were asked separately of the self-employed and employees (SE), and of unemployed and non-employed (UN), respondents. For full details of the questionnaires used in the study, see the schedules held by the ESRC Data Archive at the University of Essex; www.data-archive.ac.uk. The wording of the relevant questions here is as in DCS couples, D1 and D2. In the analysis, responses by the SEs were combined with those by the UNs, with 'wanting to work' (SEs) and 'continuing to work' (UNs) contrasted with the other responses.

19 The variables 'Future plans and confidence' in Table 3 are worded as in DCS couples C32-C35. The variable 'Past plans and achievement' in the table is worded as in DCS couples C37-C39.

20 The group in DCS who have no plans because they 'don't intend to work', with a mean age of 50, is slightly older than the other three groups (mean age of 45 , 43 and 43 respectively). Even when this group is omitted from analysis, the patterns are little changed, with 80 percent, 71 percent and 53 percent in the $\mathrm{SV}(\mathrm{Y})$, WC(Y) and WC(N) groups being 'confident'.

21 We asked our respondents a sequence of questions about the time spans over which they plan their lives, enabling us to classify them as planning: 'one year ahead or over'; 'up to months ahead', and 'up to weeks ahead'. The wording of the questions for DCS is as in DCS couples J28-J32 and for TTF as in TTF couples J25-J30. A two-way response is used in Table 5, with 'Years' contrasted with others.

22 One of the referees raised the question whether taking interaction effects into account would change the picture. In general, it would be unusual for interaction effects to be significant when the main effects, with one exception, are all insignificant. In the course of doing the analysis, we did run a model including interaction effects which made no material difference to the results, but the sample size is too small for us to have any confidence in this approach.

23 That the working class is much more divided and heterogeneous than is sometimes portrayed has, of course, been a recurrent theme in debates on class (see 
for instance Savage, 1995; Scott, 1999). We are not aware, however, of any previous work drawing attention to a tendency to exercise forethought as underlying a significant division in the working class.

24 For the reasons given in the text and in endnote 7, we cannot confidently generalize from either of these proportions to the working class in Britain as a whole. In the original SCELI study where the question was asked only of the self-employed and employed groups, the size of the $\mathrm{WC}(\mathrm{Y})$ group varied between 17 percent in Kirkcaldy and 28 percent in Aberdeen, with Coventry as an outlier at 40 percent.

25 Detailed analysis of the earlier SCELI data by Rose (2000) shows a strong linear correlation of career perception with a derived measure of 'personal skill' ('own-skill' or competence), the percentage perceiving themselves to have or have had a career rising from 14 percent in the lowest to 85 percent in the highest of six skill categories. This association is stronger than that with the skill abilities required in a post ('job-skill' or challenge).

26 Data on security in the DCS sample support this more generally. When asked about the likelihood of becoming unemployed over the next 12 months, 76 percent of the $\mathrm{WC}(\mathrm{Y})$ group and 72 percent of the $\mathrm{SV}(\mathrm{Y})$ group who were in employment said there was 'no chance'. The corresponding figure for the $\mathrm{WC}(\mathrm{N})$ group is 47 percent. In TTF the figures are strikingly different -22 percent; 15 percent and 18 percent, but this may simply reflect a lack of experience of and confidence in their labour market situation. In DCS the general pattern persists even when the sample is divided into four ten-year cohorts.

27 Our data set is not large enough to permit similar analysis of the 'deviant' service class group - those who do not perceive themselves as having a career. If our findings encourage other researchers to take these issues further, we hope that a serious effort will be made to study such a group.

\section{References}

Anderson, M., Bechhofer, F. and Kendrick, S. (1994) 'Individual and Household Strategies', pp. 19-67 in M. Anderson, F. Bechhofer and J. Gershuny (eds), The Social and Political Economy of the Household. Oxford: Oxford University Press.

Anderson, M., Li, Y., Bechhofer, F., McCrone, D. and Stewart, R. (2000) 'Sooner Rather Than Later? Preparing for Retirement Among Younger and MiddleAged Adults', Ageing and Society 20: 445-66.

Anderson, M., Bechhofer, F., Jamieson, L., McCrone, D., Li, Y., and Stewart, R. (2002) 'Confidence Amid Uncertainty: Ambitions and Plans in a Sample of Young Adults', Sociological Research Online 6(4) [http://www.socresonline. org.uk/6/4/anderson.html] (Feb.).

Arthur, M.B., Hall, D.T. and Lawrence B.S. (eds) (1989) Handbook of Career Theory. Cambridge: Cambridge University Press.

Bourdieu, P. (1984) Distinction: A Social Critique of the Judgement of Taste. (translated by N. Richard), London and New York: Routledge and Kegan Paul.

Devine, F. (1998) 'Class Analysis and the Stability of Class Relations', Sociology $32(1): 23-42$. 
Erikson, R. (1984) 'Social Class of Men, Women and Families', Sociology 18: 500-14.

Erikson, R. and Goldthorpe, J. H. (1992) The Constant Flux. Oxford: Clarendon Press.

Evans, G (1992) 'Testing the Validity of the Goldthorpe Class Schema', European Sociological Review 8(3): 211-32.

Evans, G. and Mills, C. (1998) 'Identifying Class Structure', European Sociological Review 14(1): 87-106.

Gallie, D. (1996) 'Trade Union Allegiance and Decline in British Urban Labour Markets', pp. 140-74 in D. Gallie, R. Penn and M. Rose (eds), Trade Unionism In Recession. Oxford: Oxford University Press.

Gallie, D. and Vogler, C. (1994) 'Unemployment and Attitudes to Work', pp. 115-53 in D. Gallie et al. (eds), Social Change and the Experience of Unemployment. Oxford: Oxford University Press.

Gallie, D., Marsh, C. and Vogler, C. (eds) Social Change and the Experience of Unemployment. Oxford: Oxford University Press.

Goldthorpe, J. H. (1982) 'On the Service Class, its Formation and Future', pp. 162-85 in A. Giddens and G. Mackenzie (eds), Social Class and the Division of Labour: Essays in Honour of Ilya Neustadt. Cambridge: Cambridge University Press.

Goldthorpe, J. H. (with Llewellyn, C. and Payne, C.) (1987) Social Mobility and Class Structure in Modern Britain. Oxford: Clarendon Press.

Goldthorpe, J. H. (1995) 'The Service Class Revisited', pp. 313-29 in T. Butler and M. Savage (eds), Social Change and the Middle Classes. London: UCL Press.

Goldthorpe, J. H. (2000) On Sociology: Numbers, Narratives, and the Integration of Research and Theory. Oxford: Oxford University Press.

Halford, S. and Savage, M. (1995) 'The Bureaucratic Career: Demise or Adaptation', pp. 117-32 in T. Butler and M. Savage (eds), Social Change and the Middle Classes. London: UCL Press.

Kempson, E., Bryson, A. and Rowlingson, K. (1994) Hard Times? How Poor Families Make Ends Meet. London: Policy Studies Institute.

Little, R.J.A. and Rubin, D.B. (1987) Statistical Analysis with Missing Data. New York: Wiley.

Lloyd, T. (1999) Young Men, the Job Market and Gendered Work. York: Joseph Rowntree Foundation, Work and Opportunity Series No. 8.

Marshall, G., Newby, H., Rose, D. and Vogler, C. (1988) Social Class in Modern Britain. London: Hutchinson.

McCrone, D. (1994) 'Getting By and Making Out in Kirkcaldy', pp. 68-99 in M. Anderson, F. Bechhofer and J. Gershuny (eds), The Social and Political Economy of the Household. Oxford: Oxford University Press.

Mills, C. (1995) 'Managerial and Professional Work-Histories', pp. 95-110 in T. Butler and M. Savage (eds), Social Change and the Middle Classes. London: UCL Press.

Morris, L. (1989) 'Household Strategies: The Individual, the Collectivity and the Labour Market - the Case of Married Couples', Work, Employment \& Society 3(4): 447-64.

Pahl, R.E. (1984) Divisions of Labour. Oxford: Basil Blackwell. 
Rose, M. (2000) 'Work Centrality, Work Careers and Household: Let's Ask for Numbers', Final Report to the Economic and Social Research Council on award number L212252011.

Savage, M. (1995) 'Class Analysis and Social Research', pp. 15-25 in T. Butler and M. Savage (eds), Social Change and the Middle Classes. London: UCL Press.

Scott, J. (1999) 'Class and Stratification', in G. Payne, Social Divisions. London: Macmillan.

\section{Yaojun Li}

Yaojun Li is a Research Fellow at the Centre for Census and Survey Research, University of Manchester, UK.

\section{Frank Bechhofer}

Frank Bechhofer is Professor and University Fellow at the University of Edinburgh, UK.

\section{Robert Stewart}

I Robert Stewart is Principal Consultant at MVA Scotland.

\section{David McCrone}

David McCrone is Professor of Sociology at the University of Edinburgh, UK.

Address: Institute of Governance, University of Edinburgh, Chisholm House, High School Yards, Edinburgh, EHI ILZ, UK.

E-mail: D.McCrone@ed.ac.uk

\section{Michael Anderson}

Michael Anderson is Professor of Economic History at the University of Edinburgh, UK.

\section{Lynn Jamieson}

Lynn Jamieson is Professor of the Sociology of Families and Relationships at the University of Edinburgh, UK.

Date Accepted June 2002 